\title{
Aldehyde disinfectants and health in endoscopy units
}

The report of a working party of the British Society of Gastroenterology Endoscopy Committee

R E Cowan, A P Manning, G A J Ayliffe, A T R Axon, J S Causton, N F Cripps, R Hall, P J V Hanson, J Harrison, R J Leicester, C Neumann, J Wicks

Summary of main recommendations

(1) Glutaraldehyde, used in most endoscopy units in the United Kingdom for the disinfection of flexible gastrointestinal endoscopes, is a toxic substance being an irritant and a sensitiser; symptoms associated with glutaraldehyde exposure are common among staff working in endoscopy units.

(2) The Control of Substances Hazardous to Health Regulations 1988 (COSHH) obliges the employer to make a systematic assessment of risk to staff of exposure to glutaraldehyde and institute measures to deal effectively with exposure.

(3) At present glutaraldehyde remains the first line agent for the disinfection of flexible gastrointestinal endoscopes. Other agents are being developed; a standard means of assessment for flexible endoscope disinfectants should be devised.

(4) Equipment and accessories that are heat stable should be sterilised by autoclaving; disposable accessories should be used wherever possible.

(5) Flexible gastrointestinal endoscopes should be disinfected within automated washer/disinfectors; trays, bowls or buckets for this purpose are unacceptable.

(6) Local exhaust ventilation must be used to control glutaraldehyde vapour. Extracted air may be discharged direct to the atmosphere or passed over special absorbent filters and recirculated. Such control measures must be regularly tested and records retained.

(7) Endoscope cleaning and disinfection should be carried out in a room dedicated to the purpose, equipped with control measures to maintain the concentration of glutaraldehyde vapour at a level certainly below the current occupational exposure standard of $\mathbf{0 \cdot 2}$ ppm and preferably below the commonly used working limit of $0.1 \mathrm{ppm}$. Sites other than the endoscopy unit where endoscopy is regularly performed, such as the radiology department, should have their own fully equipped cleaning and disinfection room.

(8) COSHH limits the use of personal protective equipment to those situations where other measures cannot adequately control exposure. Such equipment includes nitrile rubber gloves, apron, chemical grade eye protection, and respiratory protective equipment for organic vapours.
(9) Monitoring of atmospheric levels of glutaraldehyde should be performed by a competent person such as an occupational hygienist; the currently preferred method of sampling uses a filtration technique, the commercially available meters being less reliable.

(10) Health surveillance of staff is mandatory; occupational health records must be retained for 30 years.

(11) Endoscopy staff must be informed of the risks of exposure to glutaraldehyde and trained in safe methods of its control. Only staff who have completed such an education and training programme should be allowed to disinfect endoscopes.

(12) The unsafe use of glutaraldehyde has significant health and legal consequences; the safe use of glutaraldehyde may have revenue consequences that contribute significantly to the cost of gastrointestinal endoscopy.

\section{Introduction}

In 1988, a working party of this Society recommended aldehyde preparations (2\% activated glutaraldehyde and related products) as first line anti-bacterial and anti-viral disinfectants for flexible gastrointestinal endoscopes.' On the basis of this, glutaraldehyde is the most commonly used disinfectant in endoscopy units. In that report, reference was made to health hazards to staff from the use of glutaraldchyde and suggestions were made as to their reduction. Anxiety regarding exposure to aldehyde disinfectants, however, continued to be expressed. Therefore, the Endoscopy Section Committee of the BSG set up a working party to formulate recommendations regarding the use of aldehyde disinfectants and staff health in endoscopy units.

\section{The problem}

Glutaraldehyde is the agent used in most units for the disinfection of flexible gastrointestinal endoscopes (unpublished data). In common with other aldehydes, glutaraldehyde is toxic, irritant, and allergenic. Problems may arise from contact with liquid glutaraldehyde or its vapour.

Glutaraldehyde as an irritant - direct contact with liquid may cause an irritant dermatitis as well as exacerbate existing eczema; vapour may irritate mucous membranes of nose, throat and eyes, and also affect the respiratory tract causing 
cough and bronchospasm, especially in the asthmatic. Irritation is related to length and level of exposure.

Glutaraldehyde as an allergic sensitiser - a true allergic asthma in the previously non-asthmatic may follow glutaraldehyde exposure. This may be severe and persistent even if further exposure to aldehyde is avoided. It may also cause a true allergic dermatitis. Sensitisation usually relates to short term high peaks of exposure.

Glutaraldehyde may also cause other miscellaneous effects - these include headache, dizziness, nausea, metallic taste, yellow discolouration of skin.

Surveys suggest that the prevalence of symptoms associated with glutaraldehyde exposure is high among staff working in endoscopy units. In 1981 it was reported that staff in 16 of 48 units (33\%) had experienced problems with exposure. ${ }^{2}$ Similar results were published in 1990 with $35 \%$ of units suspecting glutaraldehyde toxicity and $63 \%$ 'harmful or potentially harmful problems'. ${ }^{3}$ Another survey reported a prevalence of symptoms of $65 \%$ and again a recent study suggested that $79 \%$ of units had at least one member of staff affected. $^{5}$

\section{COSHH and endoscopy}

The Health and Safety at Work Act 1974 requires employers to ensure, so far as is reasonably practicable, the health, safety, and welfare at work of all their employees. The Act also requires employees to comply with the precautions established to ensure safe working. The Control of Substances Hazardous to Health Regulations $1988(\mathrm{COSHH})^{6}$ require employers to assess the risks to the health of staff of exposure to hazardous chemicals such as glutaraldehyde, to avoid such exposure where this is reasonably practicable, and otherwise to ensure adequate control. Engineering means of control must be used in preference to personal protective equipment. Failure to comply with COSHH, in addition to exposing staff to risk, constitutes an offence and renders the employer liable to penalties under the Health and Safety at Work Act 1974. The Health and Safety Executive (HSE) who enforce COSHH has adopted a 10 minute time weighted average occupational exposure standard for glutaraldehyde of $0.2 \mathrm{ppm}\left(0.7 \mathrm{mg} / \mathrm{M}^{3}\right){ }^{7}$ Such standards are reviewed annually and may in the future be revised downwards. The odour threshhold for glutaraldehyde is reported to be $0.04 \mathrm{ppm}$.

$\mathrm{COSHH}$ obliges the employer to make a systematic assessment of risk to staff of exposure to glutaraldehyde and to institute measures to deal effectively with exposure. The HSE advises the following:

(1) Remove the hazardous substance by substituting a safer substance or changing the process; or, where this is not practicable;

(2) Control exposure by - enclosing the process, using extraction and ventilation equipment, and adopting safer working and handling processes $(\mathrm{COSHH}$ limits the use of personal protective equipment as the means of protection to those situations where other measures cannot adequately control exposure);
(3) Ensure that control measures are properly used, maintained, and tested;

(4) Monitor staff exposure and perform appropriate health surveillance;

(5) Educate staff on the risks and appropriate precautions to be taken.

Remove the hazardous substance:

glutaraldehyde - the case for its continued use Gastrointestinal endoscopy entails intubation through areas that are not sterile. It is important that infectious agents are not transferred from one patient to another as a consequence of using contaminated equipment.

Disinfection - eradication of vegetative bacteria and viruses - rather than sterilisation the eradication of spores as well as vegetative forms - has been regarded as adequate for routine gastrointestinal endoscopy. Flexible endoscopes are damaged by heat and are, therefore, not autoclavable. Cold disinfection by a chemical agent that does not damage their constituent parts is necessary. In a busy endoscopy list where time constraints are usually pressing a short contact time between endoscope and disinfectant is desirable.

While the transfer of any infection should be avoided, in the context of gastrointestinal endoscopy some agents have particular importance. Any disinfectant should have wide activity, particularly against intestinal bacteria, pseudomonas aeruginosa, mycobacterium tuberculosis, human immunodeficiency virus (HIV), hepatitis $B$ and $C$ virus (HBV HCV), and enteric viruses. An earlier working party report emphasised the importance of thorough cleaning of the endoscope before disinfection ${ }^{1}$; it recommended $2 \%$ glutaraldehyde and related products as the first line disinfectants, a four minute soak being sufficient to inactivate vegetative bacteria and viruses, including $\mathrm{HIV}$ and $\mathrm{HBV}$. A longer contact time of 20 minutes was advised if mycobacterium tuberculosis was strongly suspected.

Any alternative first line agent should match glutaraldehyde effectiveness within a short contact time and must not damage endoscopic equipment. This working party has carefully considered a variety of potential alternatives. The earlier report had suggested the use of $8 \%$ dettox (Dettol ED) plus $70 \%$ ethyl alcohol as a second line combination. This has drawbacks: it is a two stage process; some endoscope components may show deterioration with alcohol; concentrated alcohol is a fire hazard. Again, this combination cannot be regarded as a first line regimen.

Virkon, a preparation containing peroxygen compounds, has been the subject of much discussion. It is attractive in terms of its apparent lack of toxicity. Although many data, however, on its microbiological effectiveness are, at present, preliminary, unpublished, and thus not subjected to peer review, available information does suggest that Virkon has low activity against mycobacterium tuberculosis ${ }^{8}$ and polio virus. ${ }^{9}$ Doubts have also been expressed regarding the compatibility of Virkon with some endoscopic equipment; endoscope manufacturers have not, at present, sanctioned the use of Virkon to 
disinfect flexible endoscopes. In the light of current information, therefore, Virkon cannot be recommended as a suitable disinfecting agent for flexible endoscopes. This view may be adjusted, however, in the light of further information.

A system based on peracetic acid (Steris) results in apparent sterilisation using dedicated equipment. It has precise plumbing requirements, and a long cycle time of 30 minutes, after thorough manual cleaning. Peracetic acid is itself a toxic substance that could pose health risks to staff, which the Steris system is designed to minimise. If used in most endoscopy units it would entail the purchase of multiple sterilising systems and additional endoscopes. It cannot be recommended as a first line agent under normal circumstances but may be suitable for some sites, particularly where sterility is important such as in operating theatres.

The working party is aware that industry is active in the development of new products and that several disinfecting agents are currently receiving microbiological and equipment compatibility trials. Performance standards need to be developed by industry and microbiologists so that the suitability of agents can be assessed and compared. It is hoped that in the future glutaraldehyde may be replaced by an agent that matches it for efficacy and material compatibility but is not hazardous to staff. Until that happens there is no first line alternative to glutaraldehyde for the disinfection of flexible gastrointestinal endoscopes.

\section{Remove the hazardous substance: changing the process}

Although glutaraldehyde is the first line chemical disinfectant for flexible endoscopes, it is important to use an alternative process for endoscopic accessories wherever this is feasible, restricting glutaraldehyde to equipment that may only be disinfected by that means. Disposable accessories should be used whenever possible; sterilisation either in CSSD or in bench top autoclaves on the endoscopy unit should be used for equipment and accessories that are compatible with this process.

Control exposure by - enclosing the process The disinfection of flexible gastrointestinal endoscopes should be performed within automated washer/disinfectors after thorough mechanical cleaning including the brushing of channels. Automated machines standardise the washing/disinfecting process, are more convenient for endoscopy staff, and reduce the potential for splashing and skin contact with disinfectant. ${ }^{10}$ They do not avoid, however, the need for manual cleaning and their use can increase glutaraldehyde vapour levels. Automated machines may themselves become contaminated with micro-organisms either from endoscopes or from mains rinse water. They must be capable of self disinfection and should use sterile or filtered $(0 \cdot 2-0.45 \mu)$ rinse water. The rinse cycle must be thorough so as to remove all glutaraldehyde traces from the endoscope before its removal from the machine. The machine should dump used disinfectant to waste without it having to be drained manually.

The use of glutaraldehyde for the disinfection of flexible gastrointestinal endoscopes should be confined to appropriate automated washer/disinfectors; the use of trays, bowls or buckets, whether lidded or not, for this purpose is unacceptable.

Control exposure by - using extraction and ventilation equipment

Local exhaust ventilation must be used to control glutaraldehyde vapour arising during its activation and endoscope disinfection. This may be achieved by housing an automated washer/ disinfector within an extraction cabinet; machines are now available that perform both functions. Local exhaust ventilation systems can either discharge direct to the atmosphere or the air stream can be passed over a special absorbent filter before being returned to the workroom. Both systems have advantages and disadvantages but the HSE prefers the direct discharge of vapour to a safe place outside the building. This requires ducting to connect the extraction booth to a safe place outside the building. The discharge point should be away from openable windows, closed courtyards, and intakes for ventilation systems; it may be necessary to duct the extracted air to above roof level. If a long duct is required, installation costs may be high and more powerful extraction fans will be required to overcome duct losses. Once installed, however, maintenance costs should be less than for recirculating systems. Recirculating systems have advantages where direct discharge to outside the building would entail long ducts or difficulties with installation. Their main disadvantage is the need to change the filters regularly before they become inefficient. Therefore, an effective system needs to be operated to disclose the degree of filter saturation or time in use so that filters may be changed at an appropriate time.

The effectiveness of local exhaust ventilation must be checked often. COSHH specifies that control measures must function efficiently; they must be tested and examined at least every 14 months. Records of these tests must be kept for at least five years.

\section{Control exposure by - adopting safer working} and handling processes

Disinfection should be carried out in an area removed from other staff or members of the public to avoid any potential for their being in contact with glutaraldehyde or its vapour. The process should be sited in a dedicated cleaning and disinfection room adjacent to the endoscopy suite but separated from it by a self closing door.

The Cleaning and Disinfection Room should be designed to protect staff from contact with glutaraldehyde and its vapour. The atmosphere within the room would ideally contain no glutaraldehyde vapour but certainly less than the current occupational exposure standard of 0.2 
ppm; a suggested working limit is $0.1 \mathrm{ppm}$ (personal communication).

Activated glutaraldehyde should be confined to automated washer/disinfectors incorporating or housed in local exhaust ventilation cabinets within a dedicated cleaning and disinfection room. If endoscopy is carried out at other sites such as radiology departments these should be provided with their own cleaning and disinfection room with suitable enclosure and ventilation facilities. A less suitable alternative is to provide a sufficient number of endoscopes and accessories to permit their return for disinfection in the dedicated facilities on the endoscopy unit. The use of mobile disinfection equipment for these purposes is potentially hazardous and should be discouraged.

The use of personal protective equipment It bears repeating that COSHH limits the use of personal protective equipment to those situations where other measures cannot adequately control exposure.

Any potential contact with glutaraldehyde liquid or vapour, not contained by engineering means, necessitates the wearing of protective equipment. This should include longsleeved gloves such as Marigold 'Blue Nitrile' or 'Biogel D' surgical gloves - other latex surgical gloves are not suitable; impermeable plastic apron, chemical grade eye protection or face shield, and respiratory protective equipment suitable for removing toxic organic vapours." After use contaminated aprons should be disposed of in a container with a tight fitting lid.

If accidental spillage occurs, protective equipment as described must be used. The affected area should be closed to all unprotected staff, the spill should be contained with inert spillage granules or suitable absorbent material and the room well ventilated. All cleaning material and contaminated clothes should be disposed of immediately in a container with a tight fitting lid. Any splashes to eyes or skin should be irrigated immediately with copious cold water. Any area in which glutaraldehyde is used should be provided with a sink with running water and sterile water for decontamination.

\section{Monitor - atmospheric levels}

Monitoring of atmospheric levels can be used to record the effectiveness of control measures. An accepted technique for air sampling is the OSHA64 method ${ }^{12}$ in which air is drawn through two filters impregnated with $2^{\prime} 4$ dinitrophenyl hydrazine and phosphoric acid; the stable glutaraldehyde derivative is trapped on the filter and eluted to be analysed by high performance liquid chromatography. Commercially available glutaraldehyde meters are less reliable and subject to interference from other vapours within the atmosphere such as alcohol, perfume, and aftershave.

Atmospheric monitoring should only be carried out by a person competent in the task; occupational hygienists are trained in the monitoring and the analysis of exposure data. Static sampling may be carried out to evaluate the effectiveness of engineering control measures; 'breathing zone' samples may be collected to detect peak exposure during the performance of tasks at particular risk such as activating or decanting glutaraldehyde. It should be noted, however, that if effective engineering control were instituted such procedures would be enclosed or performed under local exhaust ventilation.

Traditionally, air sampling results have been compared with the occupational exposure standard, which is currently a 10 minute timeweighted-average level of $0.2 \mathrm{ppm}$. This value should not be assumed, however, to indicate a 'safe' level. It is known that sensitisation is most likely to occur after short high level exposure and other adverse effects are experienced at levels below the occupational exposure standard. ${ }^{13}$

\section{Monitor - staff: health surveillance}

It is not only good clinical practice but also a COSHH requirement that employees who may be exposed to glutaraldehyde receive regular health surveillance. Pre-employment health surveillance should include enquiry regarding asthma, skin, and mucosal symptoms such as those of rhinitis and conjunctivits. Pre-employment lung function testing by spirometry to measure forced expiratory volume, forced vital capacity, and peak expiratory flow rate should also be carried out. ${ }^{14}$ Employees should be reassessed annually by questionnaire for the occurrence of symptoms; spirometry on a regular basis in the absence of symptoms probably has little value. Records of occupational health surveillance should be retained for 30 years. Any symptoms occurring between regular checks should be reported to the occupational health department and investigated appropriately. If a diagnosis of occupational dermatitis or occupational asthma were to be made further exposure to glutaraldehyde should be avoided. If this is not possible the employee must be made fully aware of the risks of continuing exposure. In dermatitis, a rigorously adhered to skin care programme may permit an employee to work where glutaraldehyde is used; in asthma the use of $B_{2}$ agonists and inhaled steroids may reduce symptoms but may mask the continuing presence of airways hyper-reactivity. Further exposure to glutaraldehyde under these circumstances may lead to the continuation of asthma even after exposure to glutaraldehyde has ceased. Occupational asthma and dermatitis due to glutaraldehyde are both prescribed diseases but are not reportable to HSE under the Reporting of Injuries, Diseases and Dangerous Occurrences Regulations 1985 (RIDDOR).

\section{Educate and inform staff}

It is the responsibility of the employer to inform staff of the risks of exposure to glutaraldehyde and train them in the control measures that should be used. It is the duty of employees to take part in such programmes and to use glutaraldehyde in the safe manner in which they are instructed. ${ }^{6}$ An education and training programme might include: $\mathrm{COSHH}$ requirements; 
risks of glutaraldehyde exposure including potential symptoms; local policies and procedures; safe working methods; the role of ventilation; use of protective equipment and clothing; how to cope with spillage; health surveillance arrangements. It should entail an assessment of knowledge and practice and periodic review. Safe working procedures, including the use of personal protective equipment and spillage procedures should be available in written form and distributed to all staff taking part. Only staff who have satisfactorily completed such a training programme should be authorised to use glutaraldehyde for endoscope disinfection. Out of hours emergency endoscopy should be carried out only if endoscopy assistants are available who have been properly trained in the safe use of glutaraldehyde.

The working party acknowledges the advice of A J Chamings, Chairman of the British Occupational Hygiene Society Specia Interest Group for the Health Service, Dr CC Harling Chairman of the Association of NHS Occupational Physicians, Mrs D Campbell, Gastrointestinal Endoscopy Sister, Telford, Dr J V Collins, British Thoracic Society, and the secretarial assistance of Mrs R Feather.

This working party report was accepted by the endoscopy section committee of the British Society of Gastroenterology and approved by the Council of the British Society of Gastroenterology approved by the

Members of the endoscopy committee working party

Dr R E Cowan (chairman), Colchester General Hospital, Dr A P Manning (secretary), Bradford Royal Infirmary, Professor G A J Manning (secretary), Bradford Royal Infirmary, Professor G A J Ayliffe, Hospital Infection Research Laboratory, Dudley Road Hospital, Birmingham, Dr A T R Axon, The General Infirmary,
Leeds, Mr J S Causton, HM Inspector, HSE, Chelmsford, Mr Leeds, Mr J S Causton, HM Inspector, HSE, Chelmsford, Mr N F Cripps, Health Building Standards Manager, West Midlands RHA, Birmingham, Mr R Hall, Derbyshire Royal Infirmary, Dr London, Dr J Harrison, School of Health Care Sciences, University of Newcastle, Mr R J Leicester, St George's Hospital, London, Sister C Neumann, Gastroenterology Laboratory, Dudley Road Hospital, Birmingham, Sister J Wicks, Endoscopy Unit, Scunthorpe General Hospital.
1 British Society of Gastroenterology. Cleaning and disinfection of equipment for gastrointestinal flexible endoscopy: interim recommendations of a Working Party. Gut 1988; 29: 1134 51.

2 Axon ATR, Banks J, Cockel R, Deverill CFA, Neumann C. Disinfection in upper digestive tract endoscopy in Britain. Lancet 1981; i: 1093-4.

3 French HM. Safe use of glutaraldehyde in endoscopy units in Great Britain 1990. Gastroenterology Today 1991; 2: 48-9.

4 Calder IM, Wright LP, Grimstone D. Glutaraldehyde allergy in endoscopy units. L ancet 1992; 339: 433.

5 McAdam JG, Leicester RJ. Incidence of aldehyde sensitivity in endoscopy units. Gut 1992; 33: S52.

6 Control of substances hazardous to health regulations 1988: approved code of practice control of substances hazardous to health and approved code of practice control of carcinogenic substances. London: HM Stationery Office, 1988.

7 Health and Safety Executive. Guidance Note EH40/92. Occupational exposure limits. London: HM Stationery Office, 1992.

8 Broadley SJ, Furr JR, Jenkins PA, Russell AD. Antimycobacterial activity of 'Virkon'. F Hosp Infect 1993; 23: 189-97.

9 Tyler R, Ayliffe GAJ, Bradley C. Virucidal activity of disinfectants: studies with the polio virus. $\mathcal{F}$ Hosp Infect 1990; 15: 339-45.

10 Babb JR, Bradley CR. The mechanics of endoscope disinfection. F Hosp Infect 1991; 18A: 130-5.

11 Department of Health. Glutaraldehyde disinfectants: use and management. Safety Action Bulletin (92) 17; appendix 4

12 US Department of Labor. Occupational Safety and Health Administration. Analytical methods manual. 1987: Method 64.

13 Jachuck SJ, Bound CL, Steel J, Blain PG. Occupational hazard in hospital staff exposed to 2 per cent glutaraldehyde in an endoscopy unit. F Soc Occup Med 1989; 39: 69-71.

14 Aw TC, Barnes A. Occupational health and the use of chemical disinfectants: what is needed under the COSHH regulations. Fournal of the Institute of Sterile Service Management 1990; 1: 7-8.

Further reading

Health and Safety Executive. Introducing COSHH. Leaflet 5/90; IND $(G) 65 \mathrm{~L}$.

Health and Safety Executive. Glutaraldehyde and YOU. Leaflet Z/92; IAC 64 (L).

Z/92; IAC 64(L). Health and Sa

IND (G) 95L. Draft Approved Code of Practice. Control of respiratory sensitisers-
consultative document. Available from Sir Robert Jones Memorial Workshops, Units 3 and 5-9, Grain Industrial Estate, Harlow Street, Liverpool L8 4XY.

Babbs JR, Bradley CR, Decontamination of flexible fibreoptic endoscopy. Gastroenterology Today 1991; 1: 25-7. Campbell M, Cripps NF. Environmental control of glutaraldehyde.
Health Estates $\mathscr{f} 1991$; Nov: 2-6. 